\title{
TURISMO NA TERCEIRA IDADE
}

\author{
Sarah Strachmann Bacal'
}

\begin{abstract}
RESUMO: Analisa c rclaciona o turismo à tcrceira idade. mcdiante o enfoque da problemática da temporalidadc. Situa no lurismon a sazonalidade e seus reflexos nos setorcs de hospedaycm dos transportes c nas condiçðes da infra-estrutura hásica dos núcleos receptores. Destaca a importância de se detcrosegmento dos aposcntados. a fim de minimizar os efeitos da sazonalidade na oferla lurística. Analisa a velhice sob o ponto de vista de sua representação social. siluando o laser turístico dirigido aos "idosos sociais" como uma das opcécs para a expansão de sua sociabilidade. comunicabilidade. c o alargamento de scu universo cognitivo. Disculc. finalmentc. a adequação dos pacotes turísticos dirigidos à terceira idade. composta por pessoas da classc média no contexto populacional brasilciro.
\end{abstract}

PALAVRAS-C.HAVE: Turismo: terceira idade: sazonalidade. Terceira idade: velhice: lazer turístico: pacoles turísticos.

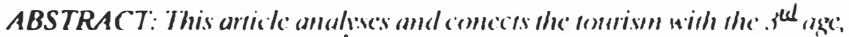

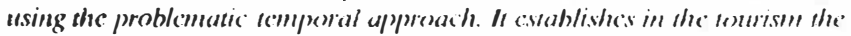

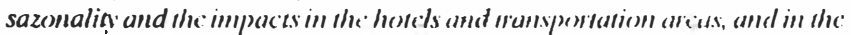

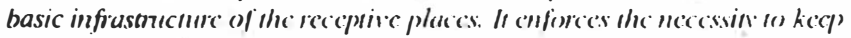

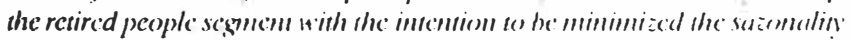
effects in the tomrism offerings. It andahes the "old age " with the perim of

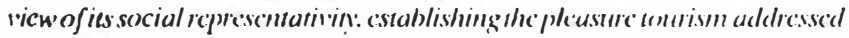
to the "old age social people" as onc of the oprisms in cypartel their

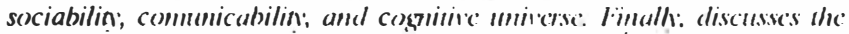

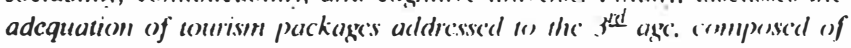

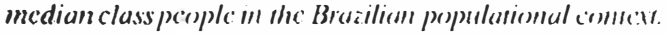

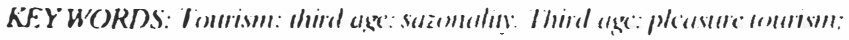
aurism packages: old agre:

1 Professora Titular do (urso de lurismo da I iscola de (omunciciés c Nitcs da USP. End. para corresp.: I:('N/USP - I)epto. de Relaçoces Públicas. Propatganda c Turismo Cidade Universitária "Armando Salles de ()livcira" - Av. Prof I. Licio Martins Rodrigues, 443 - Bloco B - (055UR-'(K) - Sào l'aulo - SP - Brasıl. 


\section{INTRODUÇĀ()}

O) tema deste trabalho remele a duas ver tentes de sil uaç̧ios ligadas à temporalidade cè tarefa de relaciona-lat, a lim de minimirar certos problemas que estao presentes em ambus: no lurismo at satomilidade $\mathrm{e}$ na aposentadoria o uso auto-conriquecedor do tcmpo.

Um dos grandes problemas do lurismo É seu aspecto sitonal, e a "terceira idade" tem como ponto central para melloriar a sua qualiclade de vida a oportunidade de relater scu orçamento-lempo, alravés do desenvolvimento de atividades que the proporcionem possibilidades de sociabilidade, comunicabilidade e expansáo do universo cognitivo. É apenas u ma fase da exisıĉncia em que o indivíduo deve deixar uma "norta aberta" para o mundo, vislumbrando por cla uma ampla gama de possibilidades (BEAUV()IR, 197()).

Um dos segmentos populacionais que se pode constituir num lluxo fora do período de alta estaçāo, e com isso diminuir significativamente os problemas gerados pela sazonalidade no turismo, é o chamado "idoso social" - o aposentado.

Com essa preocupaçāo, tenta-se situar as vantagens da explor açāo do turismo na terceira idade, quer para os agentes ceconômicos, yuer para as próprias pessoas dessisa camada da populaçāo.

\section{SAZONALIDADE N() TURISMO)}

A sazonalidade no lurismo se apresenta como um dos grandes problemas para os agentes econômicos ligados, dircla ou indirctamente, a essa atividade. Causa l ransiornos c dificuldade no selor de hospedaygem, de transporte e, também, nas condiçós da infra-estrutura básica dos núcleos receptores. Podc-sc afirmar, assim, que a sa\%onalidade sc reflete na qualidade da oferta turística

$\mathrm{Na}$ área da hospedagem cria sérias dificuldades lanto para o setor econômico, quanto para o sctor de recursos humanos. Na chamada alta estaçāo, a demanda exige maior oferta de leitos, enquanto yuc na haixa estaçāo, a capacidade ociosa dos alojamentons aumentil. Com a crise econômica por que passa o Brasil. lora das épocas de "pico" tem-se chegado até à taxa de $8(\%)$ de capacidade ociosa de hoteis. comone as da regiāo sul situados em localidades praianas. Dessal forma lorna-se praticamente impossível, para o empresário brasilciro, investir na cxpansajo de seu produto e no treinamento de maio-de-obra alocada com scus estabelecimentos.

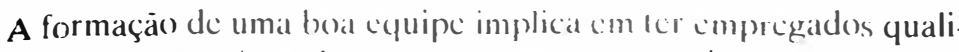
ficados com expectalivas de um progresson nal (arrciral. ()s holéis de turismo, em geral, contratam pessoal temporário quando há aumento de turistas nas férias e depois os dispensam no lírmino da estaçäo pela diminuiçāo significativa de hóspedes. Tais empercegen provisórios se traduzem, para o trabalhador, na impossibilidade de usufruis benclicios trabalhistas, como serviço médico, férias remuncradas, apoisentadoria etc., que acabam por afastar os clementos mais responsáveis que pretendem, na profissāo, segurança è ascéndencia. Por outro lado, as possibilidades de treinament() adequad() para a ma()-dc-(o)ra temporária se tornam inviáveis. Por essas raıòes a maioria dos holéis de muilos núcleos turísticos no Brasil apresentam má qualidade de prestaçāo de serviços, provocando a insatisfaçāo dos hóspedes c, numa visão macroeconômica uma oferta sem compctitividade no mercado internacional.

Quanto aos transportes, os investimentos para adequar os meios ao contexto por onde transilam e, principalmentc em relaçāo a() I ransporte aéreo, sāo inexequívcis. Nos pcríodos de alta estação) verilica-sc uma grande procura que supera a oferta, e a companhia aćréa náo lém como atender essa demanda. Por outro lado, os investimento no sclor exigem um volume maciço de capilal que não tem relorno proporcional a curto prazo, pois na baixa estaçāo há uma queda signilicativa de demanda.

Uma situação análoga sc: apresenta nos núclcos receptores em relação à adequaçào da infra-cst rutura básica, quando, péla presençáa dos turistas, há um aumento significialivo de usuários. Com isso surgem vírios problemas como a falta de água, poluiçāo, inflação non gêneros de primeira necessidade c outros transtornos que castigam a populaçāo residente pelo aumento da demanda. A médio prazo os residentes começam a considerar os turistas responsáveis pelo aviltamento de sua qualidade de vida. Robert Lanquard, em seu livro Sexcioleggies de) Turismo, coloca a seguinte situaçào:

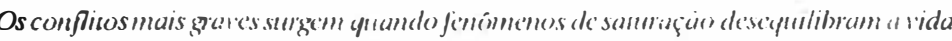

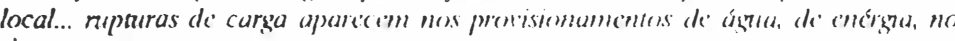

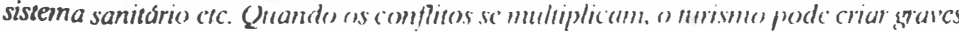

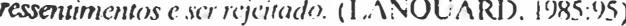

Vê-se, portanto, o quanto é necessário criar inst rumentos capazes de minimizar os efeitos da defasagem entre o volume dos lluxos turísticos nas alta e baixa estações.

Em algumas regiōes do mundo, c lambém do Brasil, um dos fatores da sazonalidade no turismo é o clima; no caso brasilciro em particular grande parte dos locais turísticos cstáo localizados em árcias de clima 
tropical com sol e calor durante todo o ano, fato que permite pensar em um turismo significativo contínuo. É preciso porém encontrar segmentos populacionais que possam viajar cm qualquer época por náo estarem atrelados aos períodos de férias escolares. Um desses scegmentos é aquele composto pelos aposentados, como se analisa a scguir.

\section{APOSENTADORIA: VELHICE SOCIAL}

Denominando aposentadoria como velhice sccial, diz MAGALHÄES (1989:10) que:

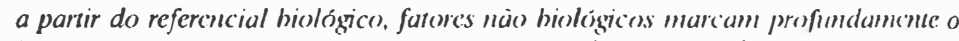

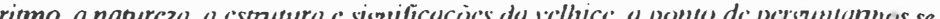

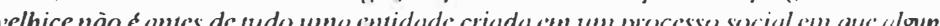
atribuein a outross pesos c inedidas.

Entre as idades tem-se a chamada terceira idade, englohando segmentos populacionais hastante diferentes. Para classificar melhor os estágios da terceira idade, pode-se considerar as idades das artérias, cronológica e social.

A idade das artérias também chamada biofisiológica, refere-se mais diretamente ao estado de saúde c ao desgaste lísico dos indivíduos de idade avançada, cuja problemálica está ligacta à gerontologia e à medicina.

Já a idade cronológica é produto de uma cult ura específica, ou mais exatamente, produto de uma representaçāo social dominante. É um tempo estrutural e estruturante que possui uma cficácia social $\mathrm{cm}$ um certo período e serve de parâmctro de leitura a loda uma sociedade que depende das representaçōes que lhe fazem os atores sociais. A mudança dessa representaçāo ć lenta c difícil, na medida em que possui uma lógica nāo-condizente com as rcais mutaçōes das condiçōes da réalidade. Por exemplo, em vários paíscs do mundo, como também no Brasil, ć considerado "idoso" para fins de recenseamento os indivíduos de mais de sessenta anos, o que pela novas condiçōes de vida nos centros urbanos nāo condiz com os indicadores da velhice biológica.

Se a idade cronológica nāo reflete a vitalidade e as expectativas de vida do homem contemporâneo, a idade social da aposentadoria traz, para um grande númcro de pessoas $\mathrm{cm}$ fasc de plena malurescência, uma série de problemas. Integram esse segmento aqueles que estáo fora do sistema produtivo e segundo os valores da sociedade industrial numa situaçāo de marginalidade. Para o extrato considerado classé média, a aposentadoria pode representar uma existência bastante problemática.
É nessa classe que se tem levantado a questào do idoso social; sāo pessoas desse extrato que, ou mobilizadas por instituiçocs ou rcunidas espontaneamente, colocam junto aos scus pares a problemática social do aposentado. Uma das instituiçoes que tem se presocupado com isso é o SESC - Serviço Social do Cómércio -, que, além de dar oportunidades de expressāo a tais pessoas, tem realizado cstudos valiosos sobre suas condiçōes.

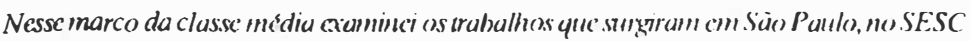
e que forain e contimuan sendo o principal refecrencial dé umina nen a práácica de cstínulo

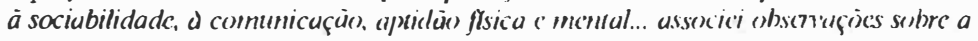

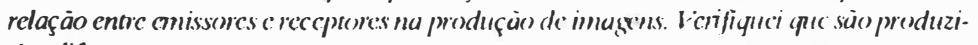
das difercnecs

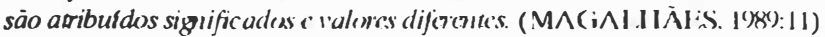

Por esses estudos, verificam-sc valores distintos relacionados à independência econômica e às atividades de trabalho informal, ou seja, surge a ocupaçāo do tempo $\mathrm{cm}$ atividades muitas vezes distintas da que exerciam, úteis e valorizadas socialmentc.

Por outro lado, a posiçāo do idoso nas relaçócs lamiliares é delicada. Suas experiências acumuladas numa realidade caractcrizada pela inovaçāo permanente e de projecto individual de vida, de realizaçāo profissional, econômica e social excluem-no, atć certo ponto do contexto vivencial da família. Isso (orna-() isolado, com baixa sociabilidade. Suas carências podem, no cntanto, ser precnchidas pelo trabalho c/ou educação informal e pelos lazcres.

Entre os lazeres o mais significativo é olazer lurisstico, pois possibilita uma sociabilidade, comunicabilidade c expansão do universo cognitivo do idoso mediante novas experiĉncias vivenciais.

A utilização do tempo livre contínuo em viagens organizadas especificamente para pessoa de terceira idade poderá servir de estímulo para relacionamento com novos grupos, aumentando, conseqüentemente, o círculo de amizades. Proporciona assim uma "abertura" no universo cognitivo, novas vivências com outros modos de comporlamentos, ou scja, uma ampla visāo sobrc lugares distintos do seu cotidiano, c, como consequência, maior repertório de informaçōes que facilita a sua prípria comunicabilidade.

\section{\ADEQUAÇÃo dOS PACOTES TURÍSTICOS À TERCEIRA IDADE}

Ao falar de turismo para a terceira idade, dirigido à classe média, o tipo de turismo mais adequado é o de grupo, onde o pacoté é preparado 
de modo a estar tudo incluído. A viagem para cssce grupo, em particular, nào deve representar apenas uma simples viagem. mas sim deve-se utilizar esse tempo para a satisfaçào dos objetivos de sociabilidade c comunicabilidade, e para a formaçào de grupos que se relacioncom durante c após a viagem. ${ }^{2}$

Considera-se que a viagem tem trés ctapas: antes, durante e depois. A fase que precede a viagem deve ser preparatória para uma convivéncia entre as pessoas, com vistas a um relacionamento humano enriquecedor. Isso pode ser conseguido at ravés de palcstras sobre os diferentes tipos de personalidade com as quais se convive, pois é na malurescéncia que as pessoas às vezes têm dificuldade em fazer concessocics. É preciso, também, estimular a curiosidade em relaçào aos locais que irāo visitar. dar informações sobre os recursos naturais e culturais das regiócs a screm visitadas. Esses encontros terào como objetivo a cocsáo do grupo e aquisiçāo de conhecimentos.

O planejamento da viagem em si deve ser leito levando-se em conta a duraçāo dos percursos, os locais de alimentação, na medida cm que nesta idade muitos passagciros fazem algum tipo dc dicta, o tcmpo ideal para cada passeio etc. É importante considerar que os idosos nào podem scguir o ritmo de uma excursào normal dirigida a jovens, por excmplo. Os organizadores precisam ter informaçoes sobre a saúde c as particularidades e cuidar para que não haja imprevistos desagradáveis $\mathrm{cm}$ relação ao bem-estar físico dos mesmos.

Importante também ć o conhecimentu das limitaçòes fisícas e fisiológicas desses usuários, para dosar as horas de viagem, as paradas e o tipo dos passeios. Todo o passecio ou atividade que exija uı maiır esforço físico deve ser informado antes, para que possaram decidir participar ou nāo; para os que nāo possam fa/ĉ-lo, oferecer alguma atividade altırnativa.

Os guias que acompanham esses passagciros devem estar preparados para tratar com pessoas de terceira idade, conhecer as inseguranças que apresentam aqueles passageiros que sacm pela primcira ve\% scm a família. Convênios médicos com instituiçôes de saúde nos locais de destino é uma preocupaçāo que os organizadores devem ter. Tal preocupaçāo deve ser do conhecimento dos passageiros. uma vc/ que proporciona uma maior segurança.

No retorno da viagem, deve-se proporcionar a continuaçāo do relacionamento já cstabclccido, mediante cncontros para exibiçāi) de

2 O turismo é o único segmento que pode cstalistecer cssc relacionamento cmirc as pessoas gratuitamente. fotografias, "slides", vídeos ctc., ou reunicoes para colher as impressóes da riagem pelos membros do grupo. É uma boa ocasiào para que o grupo planeje junto ao agente futuros rolciros.

Uma ampla campanha publicitária sobre essas viagens deve mostrar, também, as vantagens do turismo ficito na baixa estação c como se pode aproveitar os locais do Norte/Nordeste onde há "veräo" durante todo o ano.

É preciso que os hoteleiros c os responsáveis pelos transportes ofereçam tarifas especiais para aqueles que viajam fora da alı estaçāo e pertençam à terceira idade e que os órgàos públicos estabeleçam convênios e proporcionem ou estimulem o desenvolvimento de atividades de lazer e turismo, como o (.lube da Terceira Idade. ${ }^{3}$ da Secretaria de Esportes e Turismo do Estado de Sāo Paulo, que está em atividade desde 1985.

\section{$\triangle$ CONSIDERAÇÕES FINAIS}

O censo de 1990 revela que a poreentagem dos que lêm (o) anos ou mais no Brasil representa $6,8 \%$, porcentagem essa com tendência a aumentar. Isso significa que há um aumento da esperança média de vida da populaçāo brasileira, indicador social da melhoria da qualidade de vida e de bem estar social, relacionada, na verdade, às regiōes centrais ou urbano-industriais. Assim, tem-sc um segmento significitivo que poderá, inclusive, contribuir para uma compensaçäo éconônica, tal como o pensamento de SESSA (1983:44):

A instalaçüo de pélos turrsticos cm regioies detchtoras de umma atruçüon nutural, upuc se

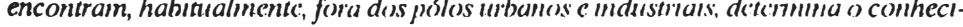
mento efeito de "compensafüo" ccomômica, que ce um! cficto de cquilihbrio territorial e, portanto, macrocconómico. A instalaçöo da atividadc turlstica c'm regioies "cuxtcmas" - fairas costeiras, marinhas ou lacustres, montanha on cammo - detcrnina um equilsbrio económico contre dias zentas do pats: aquela urbanizada c inclustrial de uma parte, brio economico cmitre ditas
aquela turstica de outra.

3 Por esse clube, as pessoas com mais de 50 anos. mediante cadast ro com carteirinha, podem usufruir de: descontos de remédios. medicamentos c clínicas: descontos de hotéis em várias cidades paulistas, que mantém convênio com a Sccrclaria: programas de excursỏes (convênio com agências operadoras): pontos de cncontro no Ginásio "Constâncio Vaz. Guimarāes (Ilirapuera) c "Bally Barionc" (Áyua Branca), fara a prática de yoga, tai-chi-chuan. croche. coral. violào: baile ("saraus") no lhirapuctra às 2.as feiras e na Água Branca às t.as fciras: Iornal da I lerccira Idadc. editado pela Secretaria com assuntos direcionados às pessoas do clubc: fincontros Nacionais da Terceira Idade - em 1991 foi realizado em Ribeirào P'reto (SI'). com aproximadamente 1500 pessoas oriundas de todo o Brasil. 
Um dos problemas que restringe os investimentos nas regioics turís. ticas "externas" é a sazonalidade. Na medida cm que for minimizada a defazagem dos fluxos turísticos entre baixa e alta cstaçāo, ter-se-á possibilidades de investimentos. Assim, procurar estimular segmentos populacionais, que possam viajar em qualquer época do ano traz beneficios às regiōes turísticas, aos agentes econômicos ligados a essa atividade e, a médio prazo, ao próprio País.

Por outro lado, o turismo para as pessoas de terceira idade pode ser uma descoberta de enriquecer a vida cotidiana, na medida em que possibilita a criação de um novo lipo de relacionamento, expansão do universo cognitivo, vivências de novas experiências de vida e a prática efetiva da comunicabilidade e da sociabilidade. As informaçōes recebidas podem ser úteis na reestruturaçāo de seu cotidiano, mediante a educaçāo ou o trabalho informal.

Sob um ponto de vista macrocconômico, scria preciso que os homens do poder público sentissem que o turismo pode scr um dos sctores econômicos que deve ser prestigiado, na medida $\mathrm{cm}$ que tem condiçōes de ajudar o desenvolvimento de regiōes consideradas carentcs, c que os mesmos atentassem para os scguintes pensamentos:

Conceder ao turismo uma face mais hmmana, se despertur c coplorar plenamone o enonne potencial que permancec udemecides cm cada indir?duce. (KRIPPENDORF, 1979)

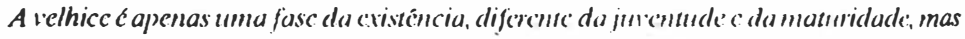

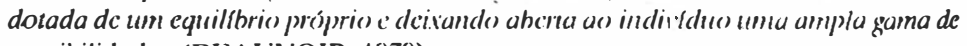
possibilidades. (BEAUVOIR, 1970)

\section{REFERENCLAS BIBLIOCFRAFICAS}

BEAUVOIR, S. 1985. A urchice: as relạ̧ōes com () mundo. São Paulo: 1)ifusào Européia do Livro.

LANGUARD. R. 1985. Sociologic du tourisme cr des rovages - Para uma nova comprecnsăo do lazer e das viagens. Rio de Janeiro: (ivilizacão Brasilcira.

MAGALHÃES, D. N. 1989. A inu cençàn social da velhice. Rio de Janciro: Papagaio.

SESSA, A. 1983. Turisino c polftica de descmollimento. Porto Nlegre: Uniontur. 